\title{
The Othering in Kazuo Ishiguro's Never Let Me Go
}

Matava Vichiensing*

English Language Studies (International Program), English Department, Faculty of Liberal Arts, Thammasat University, Thailand

Corresponding Author: Matava Vichiensing, E-mail: matava_bamboo@hotmail.com

\section{ARTICLE INFO}

\section{Article history}

Received: June 14, 2017

Accepted: August 12, 2017

Published: August 31, 2017

Volume: 8 Issue: 4

Advance access: August 2017

Conflicts of interest: None

Funding: None

\begin{abstract}
In this article, I will investigate the concept of 'othering' originally as part of a post-colonial theory. This concept is interested in many academic areas, including a literary study. In Kazuo Ishiguro's novel Never Let Me Go is about human clones raised for organs. The clones are excluded and discriminated to be 'the other' from the normal people. The manifestations of othering in Never Let Me Go can be presented in the forms of linguistic features, indoctrination, objectification, and assimilation. Although the othering phenomenon can be found in the reality, it can be appeared in literary texts as well. The findings show that the study of Kazuo Ishiguro's Never Let Me Go helps us to understand and aware of how the negative consequences of the othering process affect undesirable treatments in the society as a whole.
\end{abstract}

\author{
Key words: \\ Othering, \\ Exclusion, \\ Discrimination, \\ Post-colonial Theory, \\ Kazuo Ishiguro, \\ Never Let Me Go
}

\section{INTRODUCTION}

"I realized, of course, that other people used these roads; but that night, it seemed to me these dark byways of the country existed just for the likes of us, while the big glittering motorways with their huge signs and super cafés were for everyone else" (Ishiguro, 2005, p. 267).

As can be discerned from the excerpt above, the contemporary author Kazuo Ishiguro's sixth novel Never Let Me Go (2005) challenges his readers with the concept of 'othering' through the protagonist narrator - Kathy, who is contemplating herself as different from the rest of the society - between 'other people' and 'the likes of us'. Partly scientific, dystopian and speculative fiction, Never Let Me Go reflects unfavorable relationships between the two groups - the dominant or exploiter - 'the normals' and the exploited - 'the clones', causing the latter to become alienated, marginalized, dehumanized, or, in other words, 'othered'.

\section{Background and Significance}

Perhaps, one of the most important of othering issues is that it concerns on a human oppression. This practice of othering has been emerged from a colonial period up to a present time. In the past, the othering has occurred between the colonizer and the colonized. As Tyson (2015) pointed out, the colonizers see themselves as superior, civilized, the center of the world, and the embodiment of what a human being should be. In contrast with the colonized, the colonizers marginalize them to be the other, different, inferior, or even less than fully human. Moreover, "This practice of judging all who are different as less than fully human is called othering, and it divides the world between 'us' (the 'civilized') and 'them' (the 'others,' the 'savages')" (Tyson, 2015, p. 401). Furthermore, Culea (2014) indicates that othering, as a social, linguistic, and psychological mechanism, distinguishes 'us' from 'them', othering creates an exclusionary matrix. It also breeds inequality and further produces tension, dissention, or even conflict between members of the two groups by treating the other as an inferior. In addition, Golkowska (2014) claims that the concept of 'othering' is related to ethnocentricity and stereotyping; it always involves the domination of the in-group that declares itself superior to the out-group and denies the other subjectivity and uniqueness. For Gayatri Chakravorty Spivak (1985), 'othering' is the process by which colonial discourse creates its 'others'. "By this process, the creation of borders between those who are insiders and those who are outsiders does not occur accidently but is intended and fuelled by established social laws, principles, and practices which mark boundaries between a group and other social groups" (as cited in Ng'atigwa, 2014, 
p. 233). Interesting views affirming the problematic nature of othering are the process of categorizing individuals into two groups - one that embodies the norm and whose identity is valued, and one that is devalued, defined by its faults and susceptible to discrimination. This ultimately constructs an identity of 'the other' with their perceived degree of otherness depending on how far they deviate from the norm. From a relational perspective, self-identity is only truly known through comparisons to the ordinary and typical attributes of others who are perceived as socially normal. Once labeled as different from this prevailing norm, however, individuals are stigmatized, and it is this sense of difference that constructs their identity as other or of an 'alienated self' (Halliday, Boughton, \& Kerridge, 2014). Nowadays, the othering practices occur in many contexts such as gender, sex, race, social class, or religion.

The other is one of the familiar terms in post-colonial studies and it connects with the notion of 'othering'. In a general meaning, 'the other' is anyone who is separate from one's self. The existence of others is crucial in defining what is 'normal' and in locating one's own place in the world. The term is used extensively in existential philosophy, notably by Jean-Paul Sartre in Being and Nothingness (1943) to define the relations between self and other in creating self-awareness and ideas of identity (Ashcroft, Griffiths, \& Tiffin, 2009). According to the feminist criticism, a French feminist Simone de Beauvoir, in her book The Second Sex (1972), the category of the other is as primordial as consciousness itself. "In the most primitive societies, in the most ancient mythologies, one finds the expression of a duality - that of the self and the other" (p. 16). As Canales (2000) pointed out, "our understanding of the other is important for how we understand difference and how we engage with those perceived as different from selfas the other. This process of engagement is termed othering" (p. 16). This indicates that the others experience a feeling of frustration, shame, insecurity, and annoyance caused by the oppressors treating them differently. This is the reason why the problem of othering is worth studied.

However, the othering can be presented in any literary texts such as literary works of African American, for instance, Toni Morrison's The Bluest Eye (1970). Kazuo Ishiguro's novel Never Let Me Go is one of the literary texts that reveals the othering practices as well as a reality of human society. The novel reflects the way in which one group oppresses the other one, the oppressed group is considered as inferior, devalued, and alienated by the process of othering. Never Let Me Go imagines a world in which genetically cloned embryos are not merely conceived, but brought to term and lived existence. Moreover, the cloning depicted in the novel is both therapeutic and reproductive, in that fully developed cloned bodies are being produced in the service of medical science (Carroll, 2010). This means that the clones that are excluded from the normal human are not only seen as the other but also as an object. This indicates the significance of the relationships between the concept of othering and literary texts, which this concept can be analyzed and interpreted in any literary texts, especially Ishiguro's novel Never Let Me Go.

\section{Definitions of Terms}

In a broad sense, the concept of othering means a mental distance is created between 'us' and 'them'. A key aspect of the various theoretical approaches to othering is the observation that the notion of who and what the others are intimately related to 'our' notion of who and what 'we' are. That is, 'we' use the other to define ourselves: 'we' understand ourselves in relation to what 'we' are not. At the same time, we conceive of our group, whether a class, a nation, or a race, we define it by those we exclude from it. These outsiders are perceived as different from ourselves. They may have different languages, different customs, or beliefs. Moreover, othering is the process by which people are made to seem like an out-group -'them'- who are different from 'us', 'They' implies that individuals are members of an out-group, which is not inherently problematic; but it can be problematic if it is not purposeful, owing to the tendency to then view 'them' as inferior to 'us' (Boréus, 2001; Fitzsimmons, 2015; Kitzinger, \& Wilkinson, 1996; Littlewood \& Lipsedge, 1997).

Othering can occur by means of exclusion. According to Boréus (2001), "Exclusion occurs when human beings are deliberately excluded from a group, locked out, being deprived of goods of various types, and tends to be generally seen as unfavorable treatment" (p. 73). Additionally, exclusionary othering often uses the power within relationships for domination and subordination. The consequences for persons who experience this form of othering are often alienation, marginalization, decreased opportunities, internalized oppression, and exclusion. Exclusionary othering is often influenced by the visibility of one's otherness: skin color, accent, language, physical abilities, gender, or age (Boréus, 2001; Canales, 2000).

The othering can also appear in the form of discrimination. In this article, I am going to use this term in a specific meaning. According to Boréus (2001), discrimination is understood as unfavorable treatment of members of a group on account of their membership of that group. Discrimination is a violation of the ideal of a fair and equal society, a minimum requirement of which is that groups of people are not directly treated as inferior to the rest of the population. Discrimination makes people who are not similar or important enough belong to the same group of the mainstream. Discrimination can manifest in many forms, it is essentially a physical, emotional, or social abuse of another to reinforce or create a vertical power, hierarchical relationships, and marginalization.

\section{Research Question}

The concept of othering can be manifested in many different forms. In this article, I aim to analyze the four forms of manifestation through linguistic features, indoctrination, objectification, and assimilation. Therefore, this article aims to explore the issues and situations that othering is used. The literary text from Kazuo Ishiguro's novel Never Let Me Go will be analyzed in order to answer the following question - How does the different forms of manifestation presented in the novel? 


\section{Literature Review}

Many previous studies are relevant to the novel Never Let $M e$ Go and the notion of othering. They can be divided into two groups. The first group is the study using othering to analyze Never Let Me Go. The latter group deals exclusively with othering in any literary texts. In this section, I will synthesize these previous studies respectively in order to indicate the importance, commonalities, and differences of the novel and the notion of 'othering'.

The most relevant article dealing with the notion of othering in Ishiguro's Never Let Me Go is done by Kata (2012). Its key focus is on the construction of otherness via language. This article shows how this concept is contextualized and developed in the author's sixth novel, Never Let Me Go. Kata analyzes the book by using linguistic features as a framework called 'linguistic alienation' or 'linguistic otherness'. Linguistic alienation occurs by the use of everyday language and the only curiosity is the alienation effect employed by Ishiguro. He makes ordinary language strange and uses common words in an uncommon manner. Kata's main idea is a language could be the only means of communication but it is precisely what prevents the occurrence of real and meaningful interaction between the two parties. However, I would like to emphasize that othering is not only constructed through the linguistic features but othering, as a process, is also constructed and manifested in other forms. According to Culea (2014), "As a process, othering is unavoidably linked with the colonial age and its post-colonial critique. In addition, otherness operates at the level of the four interconnected dimensions: linguistic, social, cultural, and psychic" (p. 96). It can be a chance to fulfill the gap from the previous research by employing these forms of manifestation of othering that Kata did not mention.

The latter investigation is about the studies using the concept of othering to capture any literary texts apart from Never Let Me Go. According to Zhang (2016), August Wilson's Joe Turner's Come and Gone (1986) concentrates for the most part on the lives and experiences of his black characters; but because their lives are inseparable from those of white Americans, Wilson's work also consistently examines whiteness through a black perspective. Zhang analyzes Wilson's Otherness in Joe Turner's Come and Gone in the following sub-topics: Whiteness Means Economic Power and Economic Exploitation; Whiteness Is Social Privilege; and Whiteness Stands for Law. This study shows the economic, social, and judicial dominance of whites in America. Most importantly, whiteness for Wilson equals economic power and economic exploitation.

Moreover, Stahl (2010) investigates Yoel Hoffmann's fiction. He points out that at the center of most of Hoffmann's fiction stands the other, which often represented new immigrants, women, people of age, orphans, single parents, and widowers. However, Hoffmann does not only represent his protagonists' alterity; he also makes us experience it through the mere process of reading his texts. Hoffmann's fiction, in representing otherness, makes us experience otherness in a way that causes us to feel not at home, not only with the story of the other, but also with the text itself. Thus, it is
Hoffmann's text itself that becomes the stranger and makes us feel estranged by imitating the nature of the encounter between the self and its other. Stahl concludes that the literary text demonstrates the universal nature of language and its power to lead us to the other.

In addition, Culea (2014) studies the exploration of Chinua Achebe. The investigation focuses on the novel No Longer at Ease (1960) and the collection of autobiographical essays The Education of a British-Protected Child (2009). The study seeks to explore some of the othering practices performed by the West in its relation to the African continent, an ideological and discursive mechanism built on conceptions of darkness, difference, dehumanization, and absence. The study reveals that the rehabilitation of the African people's identity in the post-colonial environment represents a central concern for Achebe, who promotes the replacement of the colonial ideology with celebration. Its basic principle lies in the simple recognition of the other's presence and existence as a human being in the world, an attitude, which aims at transforming perceptions of the African from 'someone different' to 'one of us' in the contemporary globalized world. Achebe's appeal for artistic expression based on celebration counteracts the type of literary representation employed by the colonial genre that built its discourse on destruction, denigration, belittling, and abuse.

Correspondingly, Golkowska (2014) selects the literary work of Joseph Conrad's short story Amy Foster, for analysis. Golkowska proposes that Amy Foster can be read as a study in the mechanism of othering, which can be placed within the framework of post-colonial and gender studies. The concept of othering is related to ethnocentricity and stereotyping; it always involves the domination of an in-group that declares itself superior to the out-group and denies the other subjectivity and uniqueness. Thus understood, the term seems applicable and useful in discussing Conrad's short story. Amy Foster foregrounds the act of narration. The story revolves around issues related to voice and point of view of the protagonist, which depicts a community faced with the threat of the other. His account identifies three possible reactions to foreignness, ranging from interest in the outlandish, to rejection and downright hostility demonstrated by most of the villagers. Ultimately, what prevails and determines the course of events is the ethnocentric attitude. What Conrad does so well in Amy Foster is to show the alienation of an individual 'taken out of his knowledge'.

\section{ANALYTICAL FRAMEWORK AND REVIEW OF PRIMARY TEXT}

In this section, I will explore the origin and the development of the theoretical and methodological framework as well as demonstrating the possibility to apply this framework to my study. I will also briefly examine my selected text with its main theme and synopsis.

\section{Theoretical and Methodological Framework}

The concept of othering is not new, it can trace back, at least, to the colonialism period. As Ashcroft, Griffiths, \& Tiffin 
(2009) pointed out, the term colonialism is important in defining the specific form of cultural exploitation that developed with the expansion of Europe over the last 400 years. During this period, the other (the colonized) existed as a primary means of defining the colonizer and of creating a sense of unity beneath such differences as class and wealth. According to the post-colonial theory, "the notion of othering is developed by social scientists to articulate the post-colonial social milieu" (Ng'atigwa, 2014, p. 233). Additionally, the notion of othering and post-colonial theory cannot be separated; in other words, post-colonial theory is a background of othering. Post-colonial theory has been found useful in examining a variety of colonial relationship beyond the classic colonizing activities of the British Empire. Although the study of the controlling power of representation in colonized societies had begun in the late 1970s with texts such as Said's Orientalism, and led to the development of what came to be called colonialist discourse theory in the work of critics such as Spivak and Bhabha (Ashcroft, Griffiths, \& Tiffin, 2009). Tyson (2015) describes that a post-colonial theory offers us a framework for examining the similarities among all critical theories that deal with human oppression, such as Marxism, Feminist, LGBTQ, and African American theories. As a theoretical framework, a post-colonial theory seeks to understand the operations-politically, socially, culturally, and psychologically - of colonialist and anticolonialist ideologies.

For Ashcroft, Griffiths, \& Tiffin (2002), the term 'colonial' has been used for the period before independence and the term 'post-colonial' is to cover all the cultures affected by the imperial process from the moment of colonization to the present day. In this perspective, the notion of othering is used, as it exists during and after the period of Europeans imperial domination and the effects of these on contemporary literatures. Edward Said (1977), in his prominent work Orientalism (1978), problematizes the process of othering through duality of West/East. He describes that "The Orient is not only adjacent to Europe; it is also the place of Europe's greatest and richest and oldest colonies, the source of its civilizations and languages, its cultural contestant, and one of its deepest and most recurring images of the other. In addition, the Orient has helped to define Europe (or the West) as its contrasting image, idea, personality, and experience" (pp. 1-2). This is an example of Eurocentric othering by produce positive characteristics of Western nations by contrasting with Eastern nations in which the West projects negative characteristics such as Oriental despotism, Oriental splendor, cruelty, sensuality for The Orient. This description sets up the distinction between East and West. The West had the power to define the East as the other. Said (1977) informs us that European culture gained in strength and identity by setting itself off against the Orient. Orientalism is a subject that teaches more about European power over the Orient than it informs about the Orient. Therefore, in representing the Orient, the European conveys more about what it is to be European than what it is to be Oriental. This is evidence of the positional superiority of Europeans and cultural domination. The Orient is positioned as other. What is more, the Orient is silenced, prohibited to describe the Orient. As other, their words are powerless and meaningless. Only the Orientalist can interpret the Orient, the Orient being radically incapable of interpreting itself (Maccallum, 2002).

The concept of othering does not appear only in a post-colonial theory, but also found in feminist criticism. In addition, "feminist perspectives are of increasing importance in post-colonial criticism and indeed the strategies of recent feminist and recent post-colonial theory overlap and inform each other" (Ashcroft, Griffiths, \& Tiffin, 2002, p. 30). In feminist criticism where the patriarchal ideology reigns, woman is other: she is objectified and marginalized, defined only by her difference from male norms and values, defined by what she (allegedly) lacks and that men (allegedly) have (Tyson, 2015). Thus, the history and concerns of feminist theory have strong parallels with post-colonial theory. Feminist and post-colonial discourses both seek to reinstate the marginalized in the face of the dominant (Ashcroft, Griffiths, \& Tiffin, 2002).

Post-colonialism is also related to African-American struggles, who have suffered oppression from racial discrimination in other parts of the world. The study of black culture in the Americas as, in part, the study of one of the world's Diasporas - "the voluntary or forcible movement of people from their homelands into new region, is a central historical fact of colonization" (Ashcroft, Griffiths, \& Tiffin, 2009, p. 61). However, post-colonial theory is now used in various fields to describe a heterogeneous set of subject positions, professional, including literary field. According to Tyson (2015), there are some questions that post-colonial theory asks about literary texts. The questions are offered a post-colonial approach to literature, one of which such as: What does the text reveal about the operations of cultural difference - the ways in which race, religion, class, gender, sexual orientation, cultural beliefs, and customs combine to form individual identity - in shaping our perceptions of ourselves, others, and the world in which we live? Othering might be one area of analysis here. This also includes the case of Ishiguro's Never Let Me Go, which does not seem explicitly related to a colonialist ideology, but the notion of othering can be found and it is applicable to the text analysis.

In order to answer the research question about the othering process presented in the novel, I will be using a textual analysis and interpretation to analyze and synthesize the selected novel. Moreover, words, phrases, sentences, and discourses will be analyzed to find out how the four forms of manifestation of othering practices are revealed throughout the text.

\section{Review of Primary Text}

"The contemporary debates regarding the value of the arts and humanities, and the empathetic effects of literature on readers, are central to Kazuo Ishiguro's sixth novel, Never Let Me Go" (Whitehead, 2011, p. 56). Never Let Me Go questions at the deepest level of a human nature: 'what does it mean to be human?' and 'what makes the oppressed stay oppressed?' These questions are hidden inside Ishiguro's Never Let Me Go. A story reflects the crucial sides of lifelove, friendship, sacrifice, generosity, and memory, as well 
as the awareness of the fragility of life. Never Let Me Go provides an opportunity for the reader to reflect on the significance of othering because it conjures up characters who live in a similar world to ours but who lack the straightforward relationship to children that come from being born to human parents and having experienced the intimate first relationship necessitated by the helplessness of the infant. Technology may change the ways humans arrive in our world in the future, but for now, all humans have entered the world as infants from the wombs of human mothers. Thus, the novel provides a scenario that can be used as a test case, one whose fictionality can nonetheless illuminate the significance of othering in the world outside the novel. After all, these characters are not some radically new type of creature, completely unrelated to human beings, as we understand them. Rather, they are exact genetic copies of humans; they appear to be the same kind of beings as the people who live in the cities and towns outside of Hailsham and those who exist in the world the reader inhabits.

Never Let Me Go was firstly published in 2005 by Faber and Faber Limited. Set in England during an alternate 1990s, Never Let Me Go follows the life of Kathy, the protagonist and narrator. The story is told through her memories of her experiences in and out Hailsham, a fictional boarding school in England, late 1990s, for future 'donors'. Hailsham is an exclusive school, the teachers are known as 'guardians'. The curriculum is great emphasis on encouraging physical fitness and artistic expression and other forms of 'creativity'. Accordingly, they often emphasize the important of keeping healthy to their students. Kathy has the two closest friends, Ruth and Tommy. Never Let Me Go is related in flashback: Kathy is now thirty-one years old and about to start her first donation. For the past eleven years, she has worked as a 'carer', a nurse and companion for other clones who are in between donations. She is especially assigned to be a carer to both Ruth and Tommy. Around age sixteen, the students moved from Hailsham to a halfway house called the Cottages. At this phase, they begin contacting with the outside world. The Cottages is not the same as Hailsham, Kathy and her friends have lots of time, they are free to act as they wish. At the Cottages, there is a rumor that if two Hailsham students are truly in love, they can get their donation deferred, so they might have a few years together. Soon after, Ruth makes her second donation and 'completed'. Kathy becomes Tommy's carer and they begin a romantic relationship. Kathy and Tommy go to visit Madame and find her with the Hailsham headmistress, Miss Emily. Tommy brings his artworks with him to support his claims that he and Kathy are truly in love. When they ask about the deferral, Miss Emily kindly tells them that the deferral is never existed. Therefore, they just have to live the life that was set out for them: grow up, become a carer, donate, and complete. However, Hailsham failed due to scandal and a change of public opinion about clones. Hailsham also lost its sponsors, so it was eventually swept away. Tommy gets ready to make his fourth donation and completed. Back in the present day, a few weeks after Tommy has completed, Kathy goes to mourn him in a field in Norfolk. There, she imagines that all the things she has lost, especially Tommy, has washed up. The novel ends with Kathy turns back to the car, to drive off to wherever it was she was supposed to be.

Although Ishiguro might not be as overt in his novel $\mathrm{Nev}$ er Let Me Go about the notion of othering, when we read the text closely, this notion is carefully crafted inside the text. The conceptual insights from the post-colonial theory on the process of othering are constructed in many different forms such as linguistic features, objectification, assimilation, and indoctrination. The notion of othering can be helpful in critically analyzing Ishiguro's Never Let Me Go on patterns of control, domination, and negation of human worth. However, one thing that Never Let Me Go gives to the reader is an awareness of social inequality, unfavorable treatment, and mental impacts from the act of othering as well as in search for the ways to eliminate these results of othering in human society. Most importantly, the text tries to lead back to the fundamental question that Ishiguro attempts to ask: 'what does it mean to be human?'

\section{THE FOUR FORMS OF MANIFESTATION PRESENTED IN NEVER LET ME GO}

Kazuo Ishiguro has captured the concept of 'othering' in the text Never Let Me Go. He has created the storyline divided into three stages: The Hailsham, The Cottages, and The Recovery Center. Interestingly, the concept of 'othering' is found in all stages that he has ingeniously created. The first stage of the story is the boarding school called 'Hailsham'. This school is specially established for human clones that are brought up in this world and sent into this place since they were infants. They have grown up and educated strictly under lessons of the guardians, which are comparable to their teachers. However, these children as human clones are treated differently from the normal children. They have limited exposures to the world. They are prohibited to go beyond the school's boundary. The school is portrayed to them as a whole world. The clones are taught to believe everything that the guardians teach without questioning any facts such as who they are, who their parents are, etc. The school's guardians do not focus much about classes and knowledge of reality instead they try to make them healthy as much as they can for the future donations.

The second stage of the story is The Cottages. This place can be called the halfway house in-between 'The Hailsham' to 'The Recovery Center'. When the clones reached an adolescent period, they are sent away from the Hailsham to Cottages around the country. Kathy, Tommy, and Ruth are sent to the Cottages. In this place, not only clone students from Hailsham, but also the likes of them are placed here from many institutions. It is the very first time for them to expose the world outside the school's fences. For three of them, it takes time to adjust themselves to a new place. In contrast to Hailsham, the Cottages gives them a freedom to live without a command from anyone. Accordingly, they have more chances to expose to the real world - driving around the areas, imitating actions from reality shows, falling in love, quarreling among friends, learning fraud rumors, but most of all, experiencing the differences between 'the normal peo- 
ple' and 'the clones' as they are. The three of them, especially Kathy starts to question the existence of them.

The last stage of the story is The Recovery Center. When the clones have accomplished the first donation, they are sent to recover themselves in the recovery centers around the country in order to get ready for the second donation period. The clones who are recovering themselves in these places, 'the carer' is having responsibilities for looking after the clones. They are likely nurse and friend at the same time. 'The carer' is also a human clone. It is only duty his/ her can have in a lifetime before making their first donation. The way to prolong the clones' lives, not to start his/her first time donation too early is to be a carer at The Recovery Center. However, the concept of 'othering' can be manifested in many forms. In Never Let Me Go, I will focus only the four distinctive forms of manifestation.

\section{Linguistic Features}

Since othering, by its nature, has a characteristic of exclusion and discrimination, therefore a usage of linguistic feature is composed of a negative meaning. In order to avoid a moral sense, there is a tricky way to soften certain words, phrases, or sentences that called a euphemism - it refers to polite, indirect expressions that replace words and phrases, considered harsh and impolite or which suggest something unpleasant. In Never Let Me Go, the author uses these techniques in his narrative, for instance, Kathy - as a carer is narrating about her patient that is dying after his donations at The Recovery Center: "What he wanted was not just to hear about Hailsham, but to remember Hailsham. (...) He knew he was close to completing" (p. 5). The author uses the word 'to completing' or 'completed', which stands for to die. Furthermore, the author also uses the word 'possible', which means copying or original. There are a number of events where this term is used such as a trip to Norfolk, where Ruth pursuing her 'possible': "The point is, they claim they saw this... person. Working there in this open-plan office. And, well, you know. They reckon this person's a possible. For me" (p. 136). There is an occurrence of this term that used 'models' instead of 'possible' too: "Our models, what they were like, that's nothing to do with us, Kath. It's just not worth getting upset about" (p. 166). The quotes above indicate that the author tries to make the sense of a term 'copied' and 'original' soften by using 'possible' and 'model' instead. It reduces a hurtful feeling for the clones that have no parents, which they already perceived themselves differ from the normals. Another interesting usage is the word 'students' for the clones. The guardians always emphasize to the clones that they are students. There are circumstances, such as "For students like you, I do feel regret. It gives me no pleasure at all to disappoint you" (p. 253). However, there is an occurrence of this term in both direct and indirect ways: "Before that, all clones-or students, as we preferred to call you" (p. 256). These examples demonstrate that the clones were brought into a boarding school when they were infants. They are treated by the guardians as equally human and do not make them othered by calling them as students. The word 'students' gives the clones more comfort and not be discriminated.
Furthermore, a linguistic feature is also a tool to exclude the clones as 'the other'. Once Kathy had wondered to herself that: "we were different from our guardians, and also from the normal people outside" (p. 66). This sentence makes the clones be alienated, inferior, and devalued. Shortly after that, Kathy is aware about the donation procedures when she was at Hailsham but she did not think that was a big deal due to her innocence: "The idea was that when the time came, you'd be able just to unzip a bit of yourself, a kidney or something would slide out, and you'd hand it over. It wasn't something we found so funny in itself; it was more a way of putting each other off our food. You unzipped your liver, say, and dumped it on someone's plate, that sort of thing" (p. 86.). The word 'unzip' in this context makes the clones feel less human and be devalued. It seems like their bodies are merely an object. Later on, it has a situation where Ruth - now being an adolescent living at the Cottages with their fellow clones, talking to her friends with an outburst emotion: "We all know it. We're modelled from trash. Junkies, prostitutes, winos, tramps. Convicts, maybe, just so long as they aren't psychos. That's what we come from. (...) If you want to look for possibles, if you want to do it properly, then you look in the gutter. You look in rubbish bins. Look down the toilet, that's where you'll find where we all came from" (p. 164). This instance indicates the use of negative words and meanings such as 'trash', 'junkies', or 'gutter'. The use of these terms depicts the reduction of humanity. It makes them inferior, abnormal, devalued, and alienated. Right after that incident, there is a trip to Norfolk where is "The lost corner of England," I said, and looked around me. "And here we are!" (p. 167). This indication implicitly refers to the clones themselves. They are here metaphorically. The clones are comparable to the lost or forgotten things. They are ignored from the real world, in other words, from the normal people. The clones are also discriminated to be inferior, less human, devalued, and alienated by Madame or Marie-Claude. She is a normal person who works in partnership with the Hailsham headmistress, Miss Emily. She looks down the clones in many ways she can do. For instance, she uses the word 'Poor Creatures' to call the clones, which seems harsh for them. There are incidents when Kathy and Tommy go to her house when they both reached adulthood and Madame says these sentences to them: "Poor creatures. What did we do to you? With all our schemes and plans?" (p. 249); or "Poor creatures. I wish I could help you. But now you're by yourselves" (p. 267). She repeats this word to emphasize the superior of the normals and the inferior of the clones.

\section{Indoctrination}

The othering can be also constructed in an educational institution. Schools are not only institutions that provide children with their basic human right to educate, they also become places where teachers and children come into interact with one another (Rothmann \& Simmonds, 2015). Then, an educational setting can also manifest an othering through the indoctrination process. "Indoctrination is intended to influence targets to believe in what they are told without question- 
ing the veracity or authenticity of the conveyed information" (Ioana \& Cracsner, 2016, p. 561). We can be indoctrinated by the political, religious, and military context - especially in an educational process. In Never Let Me Go, the indoctrination process mostly occurs in Hailsham when the guardians desire to put some ideas or beliefs in order to persuade the student clones to accept it with practical aim.

There are many occurrences that an indoctrination process comes into play. For instance, Kathy has elaborated a lesson where a smoking issue is lecturing: "at Hailsham the guardians were really strict about smoking. (...) they made sure to give us some sort of lecture each time any reference to cigarettes came along. Even if we were being shown a picture of a famous writer or world leader, and they happened to have a cigarette in their hand, then the whole lesson would grind to a halt. (...) And then there were the actual lessons where they showed us horrible pictures of what smoking did to the insides of your body" (p. 67). Moreover, Miss Lucy tells the student clones “It's not good that I smoked. It wasn't good for me so I stopped it. But what you must understand is that for you, all of you, it's much, much worse to smoke than it ever was for me." (...) "You've been told about it. You're students. You're...special. So keeping yourselves well, keeping yourselves very healthy inside, that's much more important for each of you than it is for me" (p. 68). These circumstances indicate that the clones are indoctrinated by the guardians that smoking is strictly prohibited and worse for their health. However, there is a confusion of the clones of what the guardians have taught them, but in the reality, the normal people can do this thing. Another issue they were indoctrinated is about sex. At the age around thirteen, the student clones were taught about sex by Miss Emily: "how we had to be careful who we had sex with. Not just because of the diseases, but because, she said, "sex affects emotions in ways you'd never expect." We had to be extremely careful about having sex in the outside world, especially with people who weren't students, because out there sex meant all sorts of things. Out there people were even fighting and killing each other over who had sex with whom. (...) because the people out there were different from us students: they could have babies from sex. That was why it was so important to them. (...) And even though, as we knew, it was completely impossible for any of us to have babies" (p. 82). This ambiguous lecture about sex makes the clones confused such as why they cannot have babies and cannot have sex with the normals. Sex also seems harmful for the clones. Accordingly, as Kathy has questioned: "we couldn't decide whether or not the guardians wanted us to have sex or not" (pp. 94-5). The indoctrination about sex reinforces the clones to be excluded from the normals. In the following excerpt, Kathy is unveiling her belief towards Tommy: "I think I was a pretty decent carer. But five years felt about enough for me. I was like you, Tommy. I was pretty much ready when I became a donor. It felt right. After all, it's what we're supposed to be doing, isn't it?" (p. 223). This is an obvious case showing how the protagonist was indoctrinated by the educational institute when she was at a young age. She was taught to believe that she was born to do this certain duty, in this case as a donor. She has already accepted this responsibility without having any rejections.

\section{Objectification}

The term 'objectification' is generally used as a pejorative term, connoting a way of speaking, thinking, and acting to express about the attitudes and intentions of one person to another by making his/her to be objects, things, or commodities (Nussbaum, 1995). In other words, the superior treats the inferior unlike humans. This experience makes the other lose one's own selfhood as well as an absence of one's own subjectivity.

In Never Let Me Go, the objectification process is also used as one of the othering processes. In Hailsham, for instance, there is a visit of Madame that makes the clones feel uncomfortable due to her attitude and behavior: "Madame never liked us. She's always been afraid of us. In the way people are afraid of spiders and things" (p. 263). In addition, a donation process also objectifies the clones like objects or things. As Kathy has metaphorically compared herself as an object: "The idea was that when the time came, you'd be able just to unzip a bit of yourself, a kidney or something would slide out, and you'd hand it over. (...) it was more a way of putting each other off our food. You unzipped your liver, say, and dumped it on someone's plate, that sort of thing" (p. 86). Furthermore, Miss Emily tells the facts to Kathy and Tommy, who has visited her as an adult: "Before that, all clones-or students, as we preferred to call you-existed only to supply medical science. In the early days, after the war, that's largely all you were to most people. Shadowy objects in test tubes" (p. 256). It reflects an objectification in which treating the clones as a medical instrument for scientific purposes. Another incident that the clones are seen as objects rather than humans, as Miss Emily has said: "So for a long time you were kept in the shadows, and people did their best not to think about you. And if they did, they tried to convince themselves you weren't really like us. That you were less than human, (...) While that remained the case, there would always be a barrier against seeing you as properly human" (p. 258). Moreover, Kathy is aware about the donation procedures and the fate of them: "after the fourth donation, even if you've technically completed, you're still conscious in some sort of way; how then you find there are more donations, plenty of them, on the other side of that line; how there are no more recovery centres, no carers, no friends; how there's nothing to do except watch your remaining donations until they switch you off' (p. 274). The sentence above illustrates an inhuman action of the normals to the clones.

\section{Assimilation}

Othering does not only occur in a form of rejection - as objectification, which uses negative words for devaluing, excluding, and discriminating the others, but it also occurs in a form of assimilation. The key objective of assimilation is to conceal an act of objectification. The process of assimilation uses positive words or discourse for glorifying the others. Sometimes, it is called 'othering by valuing', since a 
superior group requires an acceptance and reduces a feeling of being 'the other' of an inferior group. Namely, it makes the clones feel no different from the normals in many ways. Nevertheless, an inferior group is still being discriminated and unfavorably treated.

In Never Let Me Go, the guardians use such words to call the clones for instance 'sweetheart', 'my dears', 'dear student', or 'darling'. In addition, assimilation through discourses is also used as a strategy to prove that the clones are fully human as same as the normals. For instance, Kathy and Tommy are valued when they are adults by Miss Emily on the way to visit Madame: "your art will reveal your inner selves! That's it, isn't it? Because your art will display your souls!" (p. 248). In addition, "We took away your art because we thought it would reveal your souls. Or to put it more finely, we did it to prove you had souls at all" (p. 255). The word 'soul' is used to assimilate between the clones and the normals that they are on the same level. It is because the word 'soul' implies the essence of a human. Again, Miss Emily emphasizes about the same issue: "Look at this art! How dare you claim these children are anything less than fully human?" (p. 256).

Furthermore, there are many other conversations that Miss Emily praises the clones as well as reminds them that they have raised the clones until they have reached maturity and become fully human. It is somehow to remind the clones that they owed the guardians' obligations. For instance, Miss Emily has reminded the clones of her and other guardians' obligations: "Look at you both now! I'm so proud to see you both. You built your lives on what we gave you. You wouldn't be who you are today if we'd not protected you. You wouldn't have become absorbed in your lessons, you wouldn't have lost yourselves in your art and your writing" (p. 263). In addition, Miss Emily also refers to Madame's hard working for the clones: "Marie-Claude has given everything for you. She has worked and worked and worked. Make no mistake about it, my child, Marie-Claude is on your side and will always be on your side" (pp. 263-4). Afterward, Miss Emily is trying to convince Kathy and Tommy that they have come to this point because of her: "You've had good lives, you're educated and cultured. (...) Most importantly, we demonstrated to the world that if students were reared in humane, cultivated environments, it was possible for them to grow to be as sensitive and intelligent as any ordinary human being" (p. 256). Miss Emily also gives an importance to the clones, in this case Kathy and Tommy, that she could be able to remember them all as well as their habits and reputation: "Look at the two of you. You've turned out well. I'm sure you have much you could tell me to make me proud. (...) You're the boy with the bad temper. A bad temper, but a big heart. Tommy. (...) Kathy H. You've done well as a carer. We've heard a lot about you. I remember, you see. I dare say I can remember you all" (p. 251). Lastly, Kathy and Tommy have learned from Miss Emily that in medical circles, they also valued the clones as a precious human anatomy: "A donor 'on a fourth,' even one who's been pretty unpopular up till then, is treated with special respect. Even the doctors and nurses play up to this: a donor on a fourth will go in for a check and be greeted by whitecoats smiling and shaking their hand" (p. 273). All of the above circumstances indicate that the normals are genuinely treating the clones as humans. In fact, the clones are still treated differently from the normals in many ways. It can be stated that assimilation gives the notion of 'the same but not equal'.

From the consideration of the forms of manifestation above, it is non-independently separable. Namely, some forms of manifestation can be overlapped. Linguistic features and indoctrination processes, for instance, can be overlapped by its justifications. The term 'complete' that the author uses can be a euphemism term in a linguistic features process, while an indoctrination process, this term is being cultivated into the clones' beliefs since they were young for the undeniable duty. Interestingly, there is a remark that Kathy has intentionally split the word 'die' only once to question about her duty and existence to Miss Emily: "If we're just going to give donations anyway, then die, why all those lessons? Why all those books and discussions?" (p. 254). It implicitly shows an ultimate development of Kathy's thought to reality in this situation. Furthermore, these two processes are also overlapped by the term 'carer'. It linguistically means 'a caretaker' but the author uses the term 'carer' to alienate the clones because only they can be in this position, not the normals. For Kathy, she is indoctrinated for being a good carer. She is really proud of her job: "they think I'm fantastic at what I do. There are some really good carers who've been told to stop after just two or three years" (p. 3). Besides this, a linguistic feature process can be overlapped with an objectification process. The term 'students' is used for the clones euphemistically, however, they are seen as an object in the normal people' perspective: "all clones-or students, as we preferred to call you-existed only to supply medical science. In the early days, after the war, that's largely all you were to most people. Shadowy objects in test tubes" (p. 256); as well as "It reminded people, reminded them of a fear they'd always had. It's one thing to create students, such as yourselves, for the donation programme. But a generation of created children who'd take their place in society? Children demonstrably superior to the rest of us? Oh no. That frightened people. They recoiled from that" (p. 259). Lastly, an indoctrination and assimilation processes can be crossed over too. For instance, Miss Emily as a normal is trying to praise the clones that they are 'very special' to make them assimilated to the normals. On the other hand, Miss Emily is indoctrinating the clones to believe this ideology at the same time: "You've been told about it. You're students. You're... special. So keeping yourselves well, keeping yourselves very healthy inside, that's much more important for each of you than it is for me" (p. 68).

However, the study of othering in Ishiguro's Never Let Me Go could not be found anywhere besides Kata (2012). In Kata's research, it concerns on the issue of othering by focusing only on the construction of otherness through language. This issue is similar to my research in which the terms 'linguistic features' and 'euphemism' are used to analyze the process of othering in the novel. Meanwhile, Kata does not analyze the process of othering in any other aspects, which are as important as linguistic features. In Ishiguro's Never Let Me Go reveals the othering practices through the forms 
of indoctrination, objectification, and assimilation as well. These forms of othering help us to understand the process of othering in many facets in which presented in the novel as a whole. Another issue is that the concept of othering has a post-colonial theory as its own theoretical background. It is the background of the research problem that does not appear in Kata's research.

There are also studies that use the concept of othering to analyze any other literary texts. For instance, Zhang (2016) examines August Wilson's Joe Turner's Come and Gone (1986); Stahl (2010) investigates Yoel Hoffmann's fiction; Culea (2014) studies Chinua Achebe's novel No Longer at Ease (1960) and the essays The Education of a British-Protected Child (2009); and Golkowska (2014) explores Joseph Conrad's Amy Foster. None of the mentioned researchers use the concept of othering to capture the texts on the issue of the construction or the process of othering. Furthermore, the selected texts from those studies involve around the reality, but Ishiguro's novel Never Let Me Go is about human clones in which the author fictionally creates in relations to the normal people. Those scenarios in the novel do not truly exist in the reality; however, the concept of othering can be properly used to analyze the text.

\section{CONCLUSION}

There are many aspects we learn about the concept of 'othering' and apply to the case of the clones' organ donations in Kazuo Ishiguro's novel Never Let Me Go. From a post-colonial lens, it reveals the power and oppressive nature that are hidden in the concept of othering. Moreover, a post-colonial theory helps to explain why one group of people excludes and discriminates the others. The othering, as a concept in a post-colonial theory, is broad in scope that can be integrated many disciplines with a specific interest. Likewise, I have embraced the othering concept in relation to my interest in a literary field. The othering concept in relation to Never Let Me Go seems to be a clear distinction between 'the normals' and 'the clones'; 'us' and 'them'; 'the self' and what is strange, 'the others'. However, in doing this research, it seems to be more complex than these two opposite terms. In Never Let Me Go, Ishiguro makes the post-colonial process of othering appear, which can be manifested itself in several forms as I mentioned above. It shows the ingenious ways, both direct and indirect, of the othering process. In the text, there are two groups of characters 'the normals' and 'the clones'. The social relationships of these two groups of characters are not different from those in the reality. Namely, the normals have been oppressing the clones since their early life until first to final donations and died in adulthood. Yet, the clones are not the conductors of their own lives, no freedom of choice to choose the ways to live they think they deserve, while they are treated as an object for someone else's purposes. It totally contrasts to the way of life of the normals. Additionally, the negative consequence of othering is an oppression and violation of the value of life of the clones. It is only an advantage for the normals by receiving the clones' vital organs. Furthermore, the othering process in Never Let Me Go also reflects the power relations of the inferior that could not have a power to resist against the superior's power. The clones repress their feeling of fear, suffer, and loneliness into their subconscious. Therefore, a human society in Never Let Me Go is a dystopian society as it metaphorically fits with 'The Island of Misfits', the place where someone who does not fit in belongs to, they are neither wanted nor accepted. On the other hand, Never Let Me $G o$ also reflects beautiful sides such as love, friendship, sacrifice, and memory. These experiences of the clones make their lives meaningful. In addition, some people may think that the clones are less human, no free will or even 'soul', however, the novel suggests that their artworks reveal their souls as well as their relationships and accompanying emotions that explicitly illuminate their humanness. Although we cannot completely avoid othering phenomenon, at least this article about the othering process in Kazuo Ishiguro's Never Let Me Go can raise awareness of a dire consequence of the othering.

\section{ACKNOWLEDGEMENTS}

I would like to thank Asst. Prof. Dr.Suriyan Panlay, English Department, Thammasat University, who has sacrificed his time to read, comment, and advice during the preparation of this research. All of his willingness has been invaluable to me.

\section{REFERENCES}

Ashcroft, B., Griffiths, G., \& Tiffin, H. (2002). The empire writes back: Theory and practice in post-colonial literatures ( $2^{\text {nd }}$ ed.). New York, NY: Routledge.

Ashcroft, B., Griffiths, G., \& Tiffin, H. (2009). The post-colonial studies: The key concepts (2nd ed.). London, U.K.: Routledge.

Beauvoir, S. (1972). The second sex (H. M. Parshley, Trans.). Harmondsworth, U.K.: Penguin.

Boréus, K. (2001). Discursive discrimination and its expressions. Nordicom Review, 22(2), 31-37.

Canales, M. K. (2000). Othering: Toward an understanding of difference. Advances in Nursing Science, 22(4), $16-31$.

Carroll, R. (2010). Imitations of life: cloning, heterosexuality and the human in Kazuo Ishiguro's Never let me go. Journal Of Gender Studies, 19(1), 59-71.

Culea, M. (2014). Challenging 'othering' mechanisms. Replacing African darkness and absence with the light of presence and celebration in Chinua Achebe's no longer at ease and the education of a British-protected child. Studia Universitatis Petru Maior - Philologia, (17), 93-109.

Fitzsimmons, S. R. (2015). Us, them, and others in management research. Academy of Management Review, 39(3), 73-5.

Golkowska, K. U. (2014). Empathy and Othering in Joseph Conrad's Amy Foster. Arab World English Journal, (2), 60-68.

Halliday, L. E., Boughton, M. A., \& Kerridge, I. (2014). Mothering and self-othering: The impact of uncertain 
reproductive capability in young women after hematological malignancy. Health Care for Women International, 35(3), 249-265.

Ioana, I., \& Cracsner, C. (2016). Education vs. Indoctrination. Scientific Research and Education in the Air Force, 561-574.

Ishiguro, K. (2005). Never let me go. New York, NY: Alfred A. Knopf.

Kata, G. (2012). The construction of otherness in Kazuo Ishiguro's Never Let Me Go. Első Század Online, 11(2), $407-428$.

Kitzinger, C., \& Wilkinson, S. (1996). Theorizing representing the other. In S. Wilkinson \& C. Kitzinger (Eds.), Representing the other: A feminism \& psychology reader. London, U.K.: Sage Publications.

Littlewood, R., \& Lipsedge, M. (1997). Aliens and alienists: Ethnic minorities and psychiatry. London, U.K.: Routledge.

Maccallum, E. J. (2002). Othering and psychiatric nursing. Journal of Psychiatric and Mental Health Nursing, 9(1), 87-94.

Ng'atigwa, F. X. (2014). "Othering” and "Others” in Religious Radio Broadcasts in Tanzania: Cases from Radio
Maria Tanzania and Radio Imaan. Journal of Religion and Popular Culture, 26(2), 230-243.

Nussbaum, M. C. (1995). Objectification. Philosophy and Public Affairs, 24(4), 249-291.

Rothmann, J., \& Simmonds, S. (2015). 'Othering' non-normative sexualities through objectification of 'the homosexual': Discursive discrimination by pre-service teachers. Agenda: Empowering Women for Gender Equity, 29(1), 116-126.

Said, E. W. (1977). Orientalism. London, U.K.: Penguin.

Stahl, N. (2010). "Not Being at One's Home": Yoel Hoffmann and the Formal Representation of Otherness. Prooftexts: A Journal of Jewish Literary History, 30(2), 217-237.

Tyson, L. (2015). Critical theory today: A user-friendly guide $\left(3^{\text {rd }}\right.$ ed.). London, U.K.: Routledge, Taylor \& Francis Group.

Whitehead, A. (2011). Writing with Care: Kazuo Ishiguro's Never Let Me Go. Contemporary Literature, 52(1), 54-83.

Zhang, H. (2016). August Wilson's otherness in Joe Turner's Come and Gone. Theory And Practice In Language Studies, 6(1), 171-175. 